\title{
Effect of Pregnancy on Ankylosing Spondylitis: A Case-Control Study
}

\author{
NAI LEE LUI, NIGIL HAROON, ADELE CARTY, HUA SHEN, RICHARD J. COOK, SUTHA SHANMUGARAJAH, \\ DAFNA D. GLADMAN, and ROBERT D. INMAN
}

ABSTRACT. Objective. To evaluate the effect of pregnancy on ankylosing spondylitis (AS).

Methods. Our study aimed to determine the severity of back pain and stiffness pre-, during, and postpartum in patients with AS and controls, and corresponding extraarticular symptoms.

Results. Nineteen female patients with AS (35 pregnancies) and 33 controls (77 pregnancies) were studied. Improvement in pain was reported in $51 \%$ of AS patients, predominantly in the first trimester, with significant improvement in pain than stiffness. In both groups, pain worsened in later stages, likely secondary to biomechanical loading. Postpartum pain scores in AS returned to prepartum levels in general. Conclusion. Pregnancy does not substantially aggravate disease activity or severity in AS. (J Rheumatol First Release Aug 15 2011; doi:10.3899/jrheum.101174)

Key Indexing Terms:

ANKYLOSING SPONDYLITIS

PREGNANCY

Many women with ankylosing spondylitis (AS) share common concerns about risk of disease flare during pregnancy, yet this issue has remained inconclusive, with varying results in previous publications ${ }^{1,2,3}$. This is in contrast to the beneficial effect of pregnancy on rheumatoid arthritis ${ }^{4}$. Better information would allay anxiety and allow for more sound advice to patients.

\section{MATERIALS AND METHODS}

Between February and April 2010, questionnaires were sent to 110 female patients with AS fulfilling the modified New York criteria ${ }^{5}$ and 150 controls (female psoriasis patients with no evidence of arthritis or spondylitis). Clinical data on AS (e.g., age at symptom onset and diagnosis, use of analgesics, flare of peripheral arthritis) and extraskeletal manifestations such as psoriasis, uveitis, and inflammatory bowel disease (IBD) during pregnancy were included. The Roland-Morris questionnaire was used to determine the severity of symptoms and functional impairment due to back pain ${ }^{6}$.

Outcome measures included numerical rating scales (NRS) for back pain and stiffness in pre-, during, and postpartum periods and different trimesters. Patients were considered to have improvement/worsening if there was a

From the Division of Rheumatology, University of Toronto, Toronto Western Hospital, Toronto; Department of Statistics and Actuarial Science, University of Waterloo, Waterloo, Ontario, Canada; and Department of Rheumatology and Immunology, Singapore General Hospital, Singapore.

N.L. Lui, MRCP (UK), Associate Consultant, Department of Rheumatology and Immunology, Singapore General Hospital; N. Haroon, MD, Clinical Research Fellow; A. Carty, BPH, Research Analyst, Toronto Western Hospital; H. Shen, MMath, Research Associate; R.J. Cook, PhD, Professor of Statistics and Actuarial Science, University of Waterloo; S. Shanmugarajah, BSc, Research Analyst, Toronto Western Hospital; D.D. Gladman, MD, Professor of Medicine, University of Toronto, Senior Scientist, Toronto Western Research Institute; R.D. Inman, MD, Professor of Medicine and Immunology, University of Toronto, Senior Scientist, Toronto Western Research Institute.

Address correspondence to Dr. R.D. Inman, 1E-423, Toronto Western Hospital, 399 Bathurst Street, Toronto, Ontario M5T 2S8, Canada.

E-mail:Robert.inman@uhn.on.ca

Accepted for publication June 23, 2011. change $\geq 2$ on the NRS between the different trimesters. Validation was carried out in 15 patients to determine the comprehensibility of the questionnaire.

Statistical analyses were performed using the R program, version 2.11.0. Analytical methods included Student's t test and Fisher's exact test. Responses from multiple pregnancies were treated as independent. Correlation coefficient was used to determine the magnitude of change in pain and stiffness NRS from baseline prepregnancy in different trimesters.

\section{RESULTS}

Apart from the significantly younger patients with AS, there was no significant difference in other baseline characteristics (Table 1). AS patients reported back pain in 29/35 (82.9\%) pregnancies compared to $47 / 77(61.0 \%)$ in the controls ( $\mathrm{p}=$ $0.029)$. Both groups had increased back pain and stiffness toward the later stages of pregnancy, with significantly more symptoms in the AS group (Figure 1).

Overall, $51 \%$ of AS patients reported improvement in pain during pregnancy, with worsening in $26 \%$ and no change in $23 \%$. The magnitude of pain improvement was significantly greater compared to stiffness (Figure 2). Pain reduction was particularly evident in the first trimester, with a mean reduction in NRS of $1.7(p=0.002)$ compared to prepregnancy. The pain NRS in subsequent trimesters escalated significantly, with mean increases of $1.5(\mathrm{p}<0.001)$ and $1.6(\mathrm{p}=0.004)$, respectively. No increases in flare of psoriasis, uveitis, peripheral arthritis, or IBD were reported during pregnancy.

The first month postpartum showed a trend toward less pain $(\mathrm{p}=0.072)$ and stiffness $(\mathrm{p}=0.108)$ in AS patients, with mean increases of the pain score of $1.1(\mathrm{p}=0.006)$ and $1.2(\mathrm{p}$ $=0.004$ ) from the first to the third month and third to sixth months, respectively. The level of pain and stiffness was not significantly different from baseline prepregnancy.

\section{DISCUSSION}

In this cross-sectional study, there were significant improvePersonal non-commercial use only. The Journal of Rheumatology Copyright @ 2011 . All rights reserved. 
Table 1. Baseline characteristics of patients with ankylosing spondylitis (AS) and controls.

\begin{tabular}{lccc}
\hline Characteristics & AS, & Controls, & $\mathrm{p}$ \\
& $\mathrm{N}=19$ & $\mathrm{~N}=33$ & \\
\hline Age, mean yrs (range) & $41(28-51)$ & $53(29-76)$ & $<0.001$ \\
Age at first pregnancy, mean yrs & 27.5 & 28.4 & 0.687 \\
No. pregnancies, mean & 2.05 & 2.73 & 0.116 \\
No. children, mean & 1.84 & 1.97 & 0.795 \\
No. miscarriages, mean (range) & $0.26(0-2)$ & $0.56(0-3)$ & 0.462 \\
Interval between pregnancy and study & 15 & 21 & 0.002 \\
$\quad$ questionnaire, yrs (median) & $2(10.5)$ & $2(6.1)$ & 0.617 \\
History of disc disease, $\mathrm{n}(\%)$ & $2(11.1)$ & $7(21.9)$ & 0.459 \\
History of back deformity, $\mathrm{n}(\%)$ & $1(5.3)$ & $0(0)$ & 0.373 \\
History of back surgery, $\mathrm{n}(\%)$ & & & \\
\hline
\end{tabular}

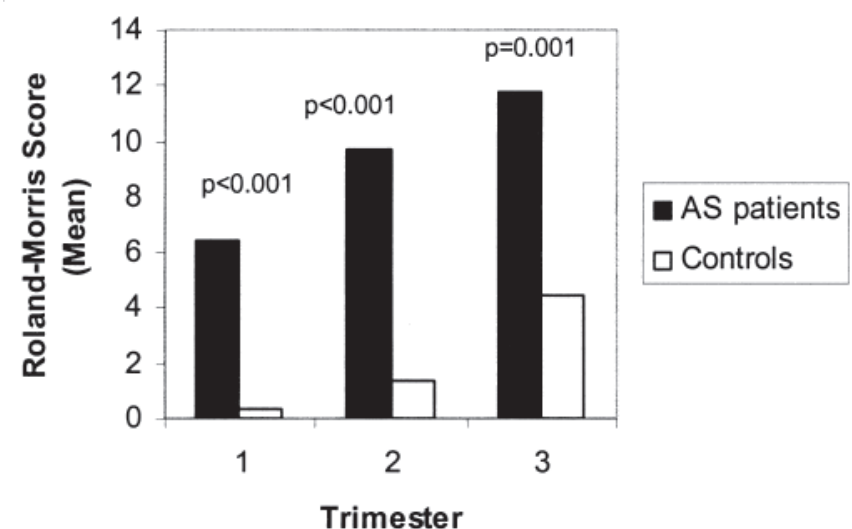

Figure 1. Comparison of back pain in AS patients vs controls based on mean Roland-Morris scores in the 3 trimesters.

ments of AS symptoms in the first trimester of pregnancy, worsening in the later stages, and some improvements in the first month postpartum. This finding differs from an uncontrolled prospective study of 9 female patients with AS that reported improvement in back pain in the third trimester ${ }^{1}$. The improvement of symptoms during the first trimester coincides with significant elevation of human chorionic gonadotrophin during the same period. Hormonal changes during pregnancy may explain the discrepancy between the magnitudes of pain improvement and stiffness, particularly when AS patients appear to return to baseline levels of back pain and stiffness postpartum.

In the spondyloarthropathy group, psoriatic arthritis patients tend to experience significant improvement during their pregnancies ${ }^{7}$, with improvement or even remission in 8 out of 10 patients $^{8}$. However, pregnancy did not seem to have any influence on patients with IBD in general, with similar flare rates during pregnancy compared to nonpregnant patients. Following pregnancy, the rate of relapse of IBD may be lower ${ }^{9}, 10$.

Back pain is common during the later stages of pregnancy $11,12,13,14$. The cause is unknown but the pain may persist several years postpartum ${ }^{15}$. In this study, both patients with AS and controls experienced worsening back symptoms in the later stages, although patients with AS had significantly more symptoms. This observation and the improvement in back symptoms in the first month postpartum suggested the role of biomechanical loading as the cause of back pain. Women with AS experienced more back pain possibly due to the following reasons: (1) low but persistently active baseline disease activity persisting in pregnancy; (2) higher tendency for mechanical back pain in AS patients; or (3) discontinuation of pharmaco- and nonpharmacotherapy for AS once pregnancy is determined, resulting in poorer control of the disease activity.

The limitations of this study included a low response rate of $23 \%$ for AS patients and 33\% for controls. Through our reminder telephone calls, we found that the majority chose not to participate due to inability in recalling their symptoms. Therefore, responders may be a self-selected group who had more significant changes in their symptoms. Recall bias is not unexpected, especially with the long median time between pregnancy and the study questionnaire. While our controls had psoriasis without clinical evidence of axial or peripheral arthritis, we could not rule out the possibility of progression of subclinical spondylitis in some patients. The other limitation was the small number of subjects, which made multivariate analysis and predictive analysis difficult. Despite the difficulty of performing this study prospectively (due to the relatively small number of female patients with AS), the results may prove clinically useful and provide some insights into the effects of pregnancy on AS. These findings should be confirmed in larger cohort studies.

Our study showed significant improvement in patients with AS during the first trimester, with significantly more improvement in pain than in stiffness in all 3 trimesters. Biomechanical effects aside, AS patients may experience significantly more symptoms due to concomitant AS disease activity. A prospective study with disease activity measurements, imaging, hormonal tests, and monitoring of inflammatory markers during the different trimesters of pregnancies is needed to confirm this observation. Our findings may provide insight into the etiology of pain and stiffness in AS, and may lead to potential development of new strategies to reduce pain and stiffness symptoms in both male and female patients with AS. 


\section{First trimester vs baseline pre-pregnancy}

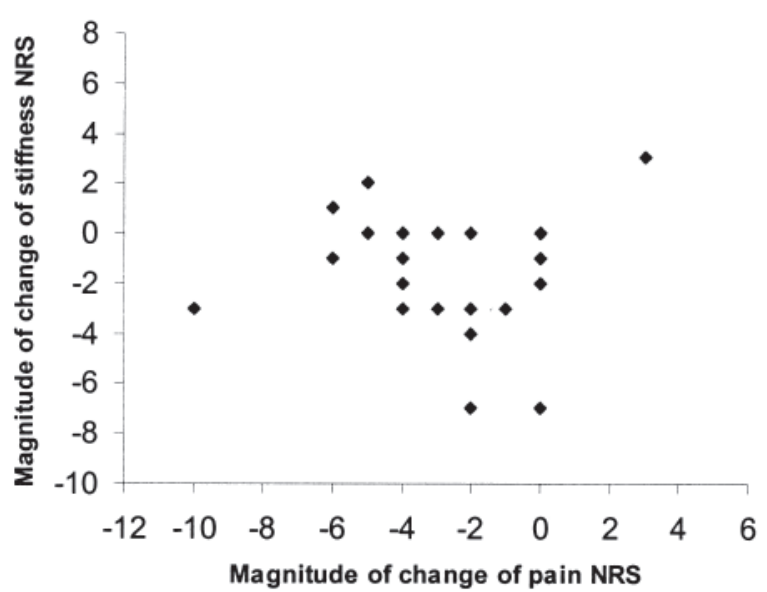

Second trimester versus baseline pre-pregnancy

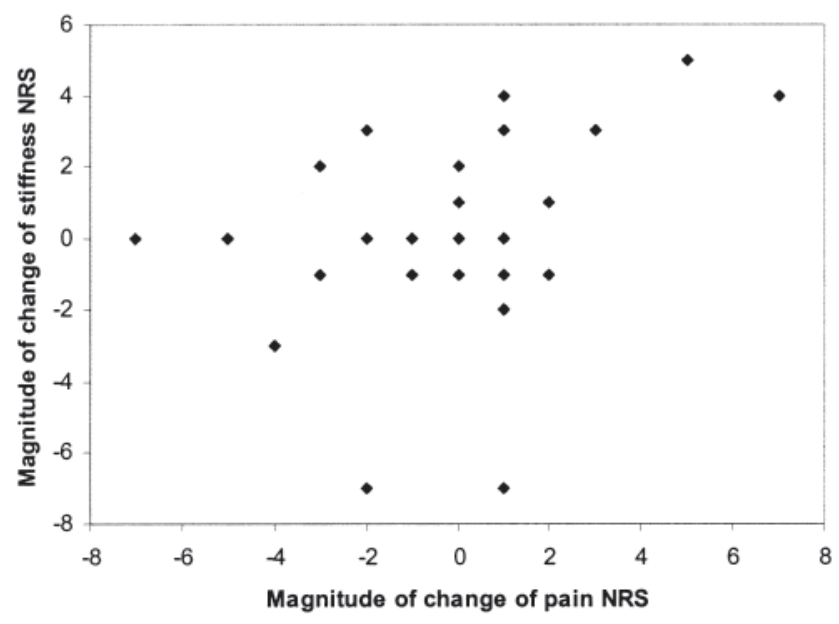

Third trimester versus baseline prepregnancy

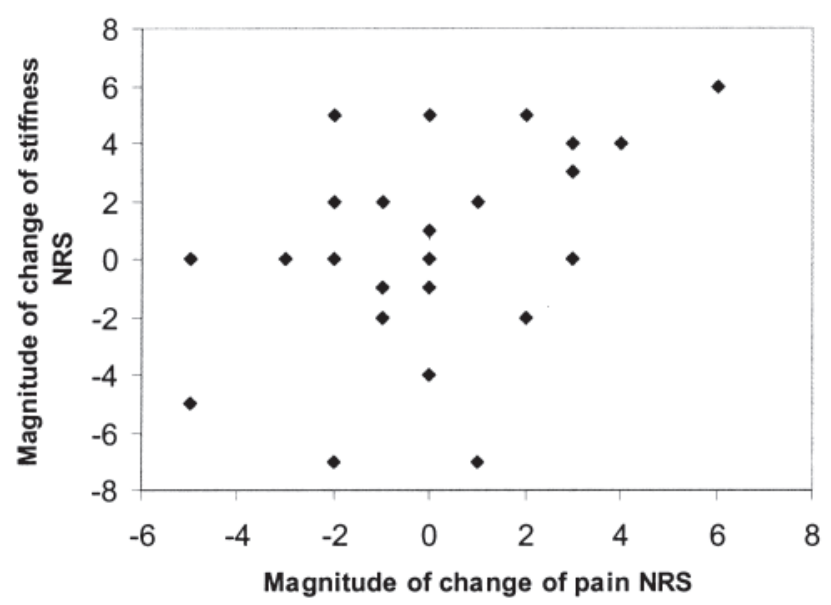

Figure 2. Scatterplots show the magnitude of change in pain vs stiffness from baseline, prepregnancy, in patients with AS. NRS: numerical rating scale.

\section{REFERENCES}

1. Østensen M, Fuhrer L, Mathieu R, Seitz M, Villiger PM. A prospective study of pregnant patients with rheumatoid arthritis and ankylosing spondylitis using validated clinical instruments. Ann Rheum Dis 2004;63:1212-7.

2. Østensen M, Østensen H. Ankylosing spondylitis - the female aspect. J Rheumatol 1998;25:120-4.

3. Østensen M, Romberg O, Husby G. Ankylosing spondylitis and motherhood. Arthritis Rheum 1982;25:140-3.

4. Perselin RH. The effect of pregnancy on rheumatoid arthritis. Bull Rheum Dis 1977:27:922-7.

5. van der Linden S, Valkenburg HA, Cats A. Evaluation of diagnostic criteria for ankylosing spondylitis. A proposal for modification of the New York Criteria. Arthritis Rheum 1984;27:361-8.

6. Roland M, Morris R. A study of the natural history of low-back pain. Part I: Development of a reliable and sensitive measure of disability in low back pain. Spine 1983;8:141-4.

7. Thumboo J, Uramoto K, Shbeeb MI, O'Fallon WM, Crowson CS, Gibson LE. Risk factors for the development of psoriatic arthritis: a population based nested case control study. J Rheumatol 2002;29:757-62.

8. Østensen M. The effect of pregnancy on ankylosing spondylitis, psoriatic arthritis, and juvenile rheumatoid arthritis. Am J Reprod Immunol 1992;28:235-7.

9. Castiglione F, Pignata S, Morace F, Sarubbi A, Baratta MA, D'Agostino L, et al. Effect of pregnancy on the clinical course of a cohort of women with inflammatory bowel disease. Ital J Gastroenterol 1996;28:199-204.

10. Riis L, Vind I, Politi P, Wolters F, Vermeire S, Tsianos E, et al. Does pregnancy change the disease course? A study in a European cohort of patients with inflammatory bowel disease. Am J Gastroenterol 2006;101:1539-45.

11. Berg G, Hammar M, Möller-Nielsen J, Thornblad J. Low back pain during pregnancy. Obstet Gynecol 1998;71:71-5.

12. Kristiansson P, Svärdsudd K, von Schoultz B. Back pain during pregnancy. Spine 1996;21:702-9.

13. Östgaard HC, Zetherstrom G, Hansson ER. Back pain in relation to pregnancy: a 6-year follow up. Spine 1997;22:2945-50.

14. Padua L, Padua R, Bondi R, Ceccarelli E, Caliandro P, D'Amico P, et al. Patient-oriented assessment of back pain in pregnancy. Eur Spine J 2002;11:272-5

15. Noren L, Ostgaard S, Johanson G, Ostgaard HC. Lumbar back and posterior pelvic pain during pregnancy: a 3-year follow-up. Eur Spine J 2002;11:267-71.

$$
\text { Personal non-commercial use only. The Journal of Rheumatology Copyright (C) 2011. All rights reserved. }
$$

